DIW BERLIN

Discussion Papers

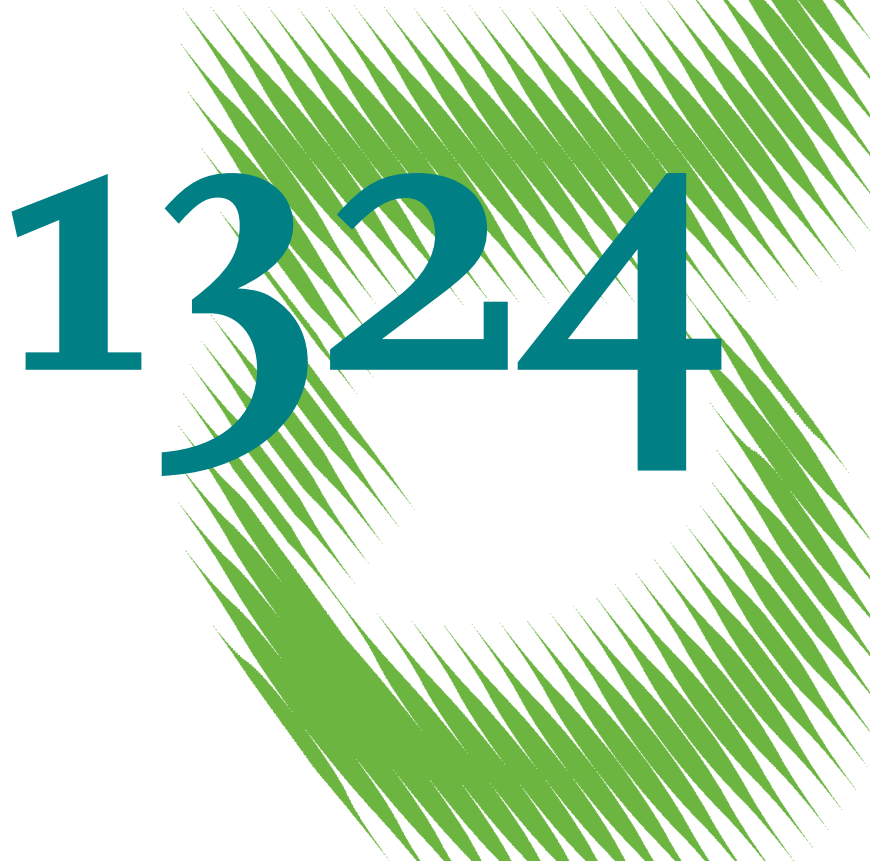

Stock Investments for Old-Age:

Less Return, More Risk,

and Unexpected Timing 
Opinions expressed in this paper are those of the author(s) and do not necessarily reflect views of the institute.

IMPRESSUM

(C) DIW Berlin, 2013

DIW Berlin

German Institute for Economic Research

Mohrenstr. 58

10117 Berlin

Tel. $+49(30) 89789-0$

Fax +49 (30) $89789-200$

http://www.diw.de

ISSN print edition $1433-0210$

ISSN electronic edition 1619-4535

Papers can be downloaded free of charge from the DIW Berlin website:

http://www.diw.de/discussionpapers

Discussion Papers of DIW Berlin are indexed in RePEc and SSRN:

http://ideas.repec.org/s/diw/diwwpp.html

http://www.ssrn.com/link/DIW-Berlin-German-Inst-Econ-Res.html 


\title{
Stock investments for old-age: less return, more risk, and unexpected timing
}

\author{
Dirk Ulbricht*
}

September 2, 2013

Returns merely based on one purchasing price of an asset are uninformative for people regularly contributing to their old-age provision. Here, each purchase has an influence on the outcome. Still, they are commonly used in finance literature, giving an overly optimistic view of expected long-term stock market returns and risks. Moreover, around business cycle turning points when volatility is high, these differences are accentuated so that the timing of market entries and exists differ substantially. This article compares risk and returns for regular and lump-sum investors for all possible intervals of investments in the Dow Jones Industrial Average ranging from one to 480 months from January 1934 to April 2013. Moreover, the optimal timing for the two types of investors in the run-up to business cycle turning points are contrasted. Lump-sum returns for forty year-horizons overstate regular contributors yields by 1.4 percentage points implying a forty percent higher terminal value. The Sharpe ratio of lump-sum investments is about 260 percent higher than for regular contributors, and the risk of negative returns disappears for horizons that are six years shorter. Increasing contributions deteriorate risk and returns. While lump-sum investors have eight months more time to switch to riskless assets before a contraction, regular contributors may return five months earlier to the stock market than lump-sum investors.

Keywords: Retirement accounts; Risk and return; business cycle; Investment management; Dollar-Cost Averaging

JEL Classification: G11; G10; E44

*dulbricht@diw.de, German Institute for Economic Research (DIW), Berlin 


\section{Introduction}

When investing in a volatile asset the number of purchases is crucial for the return. Buying only once, the return will be positive if the purchasing price is lower than the selling price. This is the scenario most of the financial literature implicitly assumes. However, if an equal sum of money is invested at an additional point in time, and the stock price is such that the average buying price is higher than the selling price, the return is negative. Investing more than once, not only the start and end price, but the history of stock prices becomes crucial to the outcome. Furthermore, each of the contributions has a different investment horizons, as they will only be available at different points in time. Therefore, the internal rate of return rather than the geometric mean of the first purchasing and the selling price commonly used is needed. This is highly relevant for most of the average earners, laying aside a fixed part of their monthly income for old-age provision. Thus, there are two fundamentally different ways of looking at investments, from the perspective of investors that contribute only once (lump-sum investors, LS) and those, that are regularly contributing money to a portfolio (regular contributors, $\mathrm{RC}$ ).

Dollar Cost-Averging (DCA) is frequently confounded with regular contributions. Under the DCA strategy a lump-sum investor does not invest all her money at once but rather spreads her purchases over different moments in time with the aim of avoiding the purchase at a market high. As with regular contributors, there are different purchases. However, more importantly, all money is available right from the start and implicitly invested over the same investment horizon. The money that is not directly used for buying stocks can be invested in riskless assets, for example. Thus, the returns are calculated as the geometric mean based on the initial and the terminal wealth. Though a considerable literature analyzes DCA and demonstrates its inferiority to lump-sum investments, little can be learned with respect to regular investments.

Experts giving advice to normal investors usually do not discern between the returns of a lump-sum and regular contributions. In his famous guidebook, Malkiel [2003], for example, makes projections of future stock returns based on a comparison of four eras of stock and bond market returns. He is eager to point out, that his projections do not imply anything for a specific period of time such as ten years or less but rather for the longer run. Looking at longer period's returns, however, it is even more important to use the right returns for each purpose. The longer the distance between the first and the last purchase, the larger the differences between the horizons each of the contributions are invested. Investing in stock markets, for example, shorter investment horizons have higher expected returns and higher volatilities than long-term investments. Thus, the differences tend to increase with the time between the first and the last transaction. Therefore, expected lump-sum returns and their variability are not adequate when assessing regular investments such as old-age provision schemes. Moreover, as income tends to rise with work experience, and as a reflection of inflation, so do contributions to old-age provision schemes. This will give more weight to contributions, that are invested shorter periods. Lump- 
sum returns only being the return of the first contribution should then even be less informative of the average return of all contributions.

A large number of papers analyzing lump-sum investments emphasize the merits of stock market investments. While we frequently see periods of falling prices lasting several years, ruining some unlucky investors who hold their assets only few years. Still, if the investment horizon is extended over thirty or forty years, the probability of losing money will be reduced to zero, at least historically and in nominal terms. Moreover, on average the excess return over risk-free investments such as government bonds is remarkable. As it seems, it only takes strong nerves to overcome bearish markets to be rewarded amply. However, it remains unclear, how regular investments compare to that.

Certainly, beginning with the second period, every regular investor becomes a lump-sum investor, as well. Then, the existing wealth and the fresh money need to be decided upon. Turning Samuelson's famous sentence that stock markets predicted nine out of five recessions on its head, stock markets will react to business cycle turning points. In anticipation of an economic contraction, stock markets plummet, in the run-up to an expansion, they soar. Investors try to reallocate their assets from risky assets like stocks to save havens such as government bonds, or vice versa. In doing so, timing is crucial. In the best of all cases, the investor pulls her money out of the market before suffering losses to return when quotes are rising again. When compared to normal times, turning points coincide with high volatilities. When volatility is increasing, so will differences in lump-sum and regular investments. As a consequence, investment timing around turning points is likely to differ, as well.

This paper highlights the differences between the returns of lump-sum investments and regular investments in the Dow Jones Industrial Average. It demonstrates that commonly used returns are not informative when regular investors saving money for old-age are concerned. Returns are over-estimated and risks are significantly underestimated. First, the comparison focuses on the mean differences as a result of growing investment horizons from one to 480 months, taken over all possible time intervalls. As a baseline, the mean returns, the Sharpe ratios and the probabilities of negative returns are compared for lump-sum investments and regular investments that are not growing over time. Mean returns are higher for regular investments, when contribtuions are constant. However the risk-return ratio is much more favorable for lump-sum investments especially for longer horizons, the Sharpe ratio being 260 percent higher. For regular investments, the probability of losses is higher and it takes horizons to be five years longer than for lump-sum invesments to reduce it to zero. When the results are compared to the more realistic scenario of increasing contributions, yields of lump-sum investments are 1.4 percentage points higher than for regular investments for forty year horizons, implying a forty percent higher terminal value. Both the risk-return ratio and the probability of negative returns deteriorate further in comparison to constant contributions. Looking at the most basic investment decision between an investment into the risk-free rate and into the stock market, it is shown, that the right timing differs between the two. Prior to expansions, regular investors or lump-sum investors following 
DCA may return earlier to the stock market than LS investors. In contrast, LS investors have more time to leave the stock market without losses than RC and DCA in anticipation of a recession.

Section 2 gives an overview of the relevant literature. Section 3 introduces the data and the methodology of computing the two different measures of return. Section 4 presents the results and section 5 concludes.

\section{Literature Overview}

Most of the existing investment literature concentrates on the challenge of investing a given amount of money when there are no additional funds other than the returns of the investment itself. An important practical issue adressed is to choose the right moment to buy and sell the asset. In order to prevent investors from buying at the wrong time, popular investment literature, as for example Malkiel [2003], suggests spreading the investment into equal parts over some months or years (DCA). In contrast to the popular view, academic literature shows the superiority of lump-sum investment over DCA. Though DCA returns can not be used to assess regular contributions, some of the arguments put forward against DCA may also be applied to regular investments being the focus of the current analysis.

Investing in the same assets over longer horizons is not optimal from a riskreturn point of view. Constantinides [1979] demonstrates theoretically that sequential investment strategies not strictly adhering to past decisions like DCA but rather using up-coming information to optimize the portfolio, will lead to higher utility. Comparing the empirical certainty equivalents of DCA and lumpsum investment strategies from one to six years, Brennan et al. [2005] for valueand equal-weighted market portfolios find that the former lead to better results. Value-weighted portfolios sell assets, if their relative value with respect to the other assets rise, and vice versa. Thus, this strategy is reacting to up-coming information, in the best of all cases realizing profits and buying undervalued assets.

As pointed out, the term structure of longer and shorter investment horizons tend to increase expected returns and volatility. However, averaging out extreme prices, buying at different instances not only reduces the risk of buying at the wrong time but also reduces the chance of buying at the right time. Leggio and Lien [2003] address both aspects. They test DCA against three alternative investment strategies using the Sortino ratio and the Upside Potential ratio finding DCA to be suboptimal. With LS investment, all of the money is immediately invested in the riskier but also more lucrative stock market when compared to DCA. Thus, Rozeff [1994] adequately reduces the amount of money invested in the stock market after using LS in order to compare the two strategies. He concludes that as long as there is a positive expected return then those who hesitate, lose money. In a theoretical approach modeling stock returns as ARMA $(1,1)$ Balvers and Mitchell [1997] show that a gradual market entry, even if the investments are not made at fixed amounts, represents a suboptimal strat- 
egy. Vanduffel et al. [2012] propose a static strategy consisting of purchasing a suitable portfolio of path-independent options that will dominate DCA for all risk-adverse investors. They provide evidence that the relative performance of DCA is worse in volatile markets, exactly where it is supposed to be most helpful. However, Trainor [2005] shows that the within-horizon risk, that is the risk of having huge negative returns when selling prematurely, is significantly reduced when DCA is applied.

In a closely related approach to the one presented here Dichev [2007] introduces the concept of value-weighted returns. In contrast to the usual yearon-year returns based on the first and the last price of a security, he takes the capital in- and out-flows to a portfolio as a consequence like stock repurchases or dividends into account. On the basis of these, the initial buying price as a negative cash-flow, and the selling price as a positive cash-flow he derives an internal rate of return of the portfolio. When contrasted with the return calculated as the geometric mean only taking the buying and selling price into account, he shows, that the value-weighted returns are significantly lower. As he intends to contrast the classical returns to the ones found using the new methodology he compares annual returns. However, as he acknowledges, the returns are highly dependent on the path of the security over time. Thus, his results only apply for a lump-sum investor investing at the beginning of the year and selling at the end of the year.

Malliaris and Malliaris [2008] compare the terminal values of constant regular investments into a broad portfolio of stocks when calculated on the bases of the actual monthly return sequences to the ones calculated on the bases of the geometric mean of the monthly returns. They show that the outcomes only accidentally coincide and conclude that geometric means do not adequately reflect the term structure of returns of regular investments. However, they do not calculate internal rates of returns, which are necessary to compare risk and return along investment horizons, but rather present average monthly returns. They implement their analysis for intervals of twenty, thirty or forty years, starting at different points in time. Because of the long overlap of identical investment horizons, the variability of accumulations based on the actual return sequence is lower than if they were based on the geometric mean.

Fama and French [1989] demonstrate expected returns on common stocks and long-term bonds to contain a term or maturity premium that has a clear business cycle pattern. Their main conclusion is that expected returns are lower when economic conditions are strong and higher when conditions are weak. DeStefano [2004] shows that stock returns and the business cycle, as measured by the National Bureau of Economic Research (NBER) are inversely related. Returns decrease throughout expansions and are negative in the first half of recessions. In the second half of recessions they are highest. Siegel [1991] shows that expected returns significantly fall before NBER recessions and rise before expansions, so that it can be profitable to flee into save havens such as government bonds before business cycle peaks and to re-enter before a trough. If an investor was able to correctly predict the turning points a switch between shortterm riskless assets and stocks with a lead of four months maximizes profits. 


\section{Data and Method}

The monthly Dow Jones Industrial Average series (end-of-month values), the risk-free investment given as the three month treasury-bill rate and the consumer price index (CPI) are taken from Federal Reserve Economic Data. The observations range from January 1934 to April 2013. The peaks and troughs are taken from the most recent decision of the Business Cycle Dating Committee of the NBER, as of September 2010.

The different investment strategies are evaluated comparing the outcomes of hypothetical investments made over different investment horizons, $h$, starting at different points in time, $s$. The contribution of regular investments is allowed to increase by the rate of $g$. The returns of regular investments calculated here are the internal rates of return (IRR). First the terminal value (TV) of the stock market or riskless investment is computed. Its IRR is the time invariant return of an hypothetical investment giving the same TV for the same contributions invested at the same points in time. The TV of a regular contribution invested in the DJIA is the sum of the shares obtained throughout the investment horizon at $t=s, \ldots, s+h-1$ at the start of each month times the selling price $p_{s+h}$,

$$
T V_{R C, D J I A, s, h}=\left(\Sigma_{t=s}^{s+h-1} \frac{(1+g)^{t-s+1}}{p_{t}}\right) \times p_{s+h} .
$$

The TV of a regular contribution invested in the riskless security paying a time varying interest of $i_{t}$ is calculated as

$$
T V_{R C, \text { riskless }, s, h}=\Sigma_{t=s}^{s+h-1}(1+g)^{\tau-s+1} \times \Pi_{\tau=t}^{s+h-1}\left(1+i_{\tau}\right)
$$

The TV are used to identify the IRR of the regular investments, $y$ being the time-invariant return of a regular contributed investment with identical invested sums and timing, solving

$$
0=\Sigma_{i=1}^{h}\left(1+y_{R C, a, s, h}\right)^{h-i+1} \times(1+g)^{i}-T V_{R C, a, s, h}
$$

for $y_{R C, a, s, h}$, where $a$ may either be $R C$ or riskless.

The terminal value of a lump-sum investment in the stock market is calculated as $T V_{L S, D J I A, s, h}=\frac{p_{s+h}}{p_{s}}$, and the terminal value of a lump-sum investment in the risk-free security as $T V_{L S, \text { riskfree }, h, h}=\Pi_{t=s}^{s+h-1}\left(1+i_{t}\right)$. Let $S V_{D C A, s, h}$ be the start value of the DCA investment. The first period, $\frac{S V_{D C A, s, h}}{h}$ is invested and the remaining $\frac{S V_{D C A, s, h}}{h} \times(h-1)$ is invested in the riskless asset at the interest rate $i_{s}$, so that at the beginning of the second period $\frac{S V_{D C A, s, h}}{h} \times(h-1) \times\left(1+i_{s}\right)$ are still not invested in the stock market. A share of $\frac{1}{h-1}$ of this sum will then be invested in the stock market and the remaining share of $\frac{h-2}{h-1}$ is invested in the riskless asset at $i_{s+1}$, and so forth, giving

$$
T V_{D C A, s, h}=\left(\frac{S V_{D C A, s, h}}{p_{s} \times h}+\sum_{t=s+1}^{s+h-1} \frac{S V_{D C A, s, h} \prod_{\tau=s}^{t-1}\left(1+i_{\tau}\right)}{p_{t} \times h}\right) \times p_{s+h} .
$$


The yields are $y_{L S, a, s, h}=\sqrt[h]{T V_{L S, a, s, h}}-1$, where $a$ may either be $R C$, riskless, or DCA.

\section{Results}

\subsection{Comparing different investment horizons}

It is highly unrealistic that an investor lays back an equal dollar-sum each month over longer periods such as ten years or let alone the maximum 40 years analyzed here. However, setting $g=0$ is a very informative point of reference to work out some specific differences between LS and RC when relaxing this constraint, that is if $g>0$. Consider the plots in figure 1 .

The plots in the first column give means of RC and LS, the second column the corresponding Sharpe ratios, and the third column the probabilities of suffering a loss yield. As the scales of the results differ widely along the investment horizons, the plots are split over three intervals to facilitate the analysis.

The three plots in the first column of the figure compare the mean yields, where the means are taken over the returns of each investment horizon. The first row gives the results for horizons of one to twelve, the second row horizons of 13 to 120, and the third row horizons of 121 to 480 months. As fewer windows can be calculated as the investment horizon expands, the mean of the one month investment is taken over 951 observations, while the mean of the longest investment horizon of 480 month is taken over 472 observations. As there is no difference between the lump-sum and the regular investment with at horizon of one month the results are identical.

Both, the means of LS and RC are highest for very small horizons giving mean returns of about 21 percent for one-month horizons. The mean yields are declining sharply from one to two months, and continue to fall at a decreasing rate. Then, yields fall until a minimum of about 6.5 percent is reached for horizons of four years to rise to a second peak of about 7 percent for horizons of 17 years (LS) and 21 years (RC). Eventually they decline for longer horizons, giving a mean of 6.1 (LS) and $6.5(\mathrm{RC})$ percent.

For horizons from 2 to 12 months, LS returns are 0.8 percentage points (two month horizon) to 0.53 percentage points (12 month horizon) lower than $\mathrm{RC}$ returns. The gap is narrowing from one to ten years to 0.2 percentage points, and from 10 to about 18 years (170 month horizon) to 0.1 percentage points. Starting with the 420 month horizon, the gap starts growing, reaching approximately 0.4 percentage points at the 480 month horizon.

Though the means of LS are never higher than the means of RC, the riskreturn ratios, give a considerably different picture. The Sharpe ratio (SR) is the mean of the excess return over its standard deviation, $S R=\frac{\text { mean }\left(y_{i}-y_{\text {riskless }}\right)}{s d\left(y_{i}-y_{\text {riskless }}\right)}$. Higher volatility of excess returns is not desirable and will lead to a decrease in the Sharpe ratio, whereas a higher mean excess return leads to an increasing Sharpe ratio. Like the mean returns, the Sharpe ratio is higher for RC than for LS for horizons ranging from two to 19 months. Still, the relative differences of 

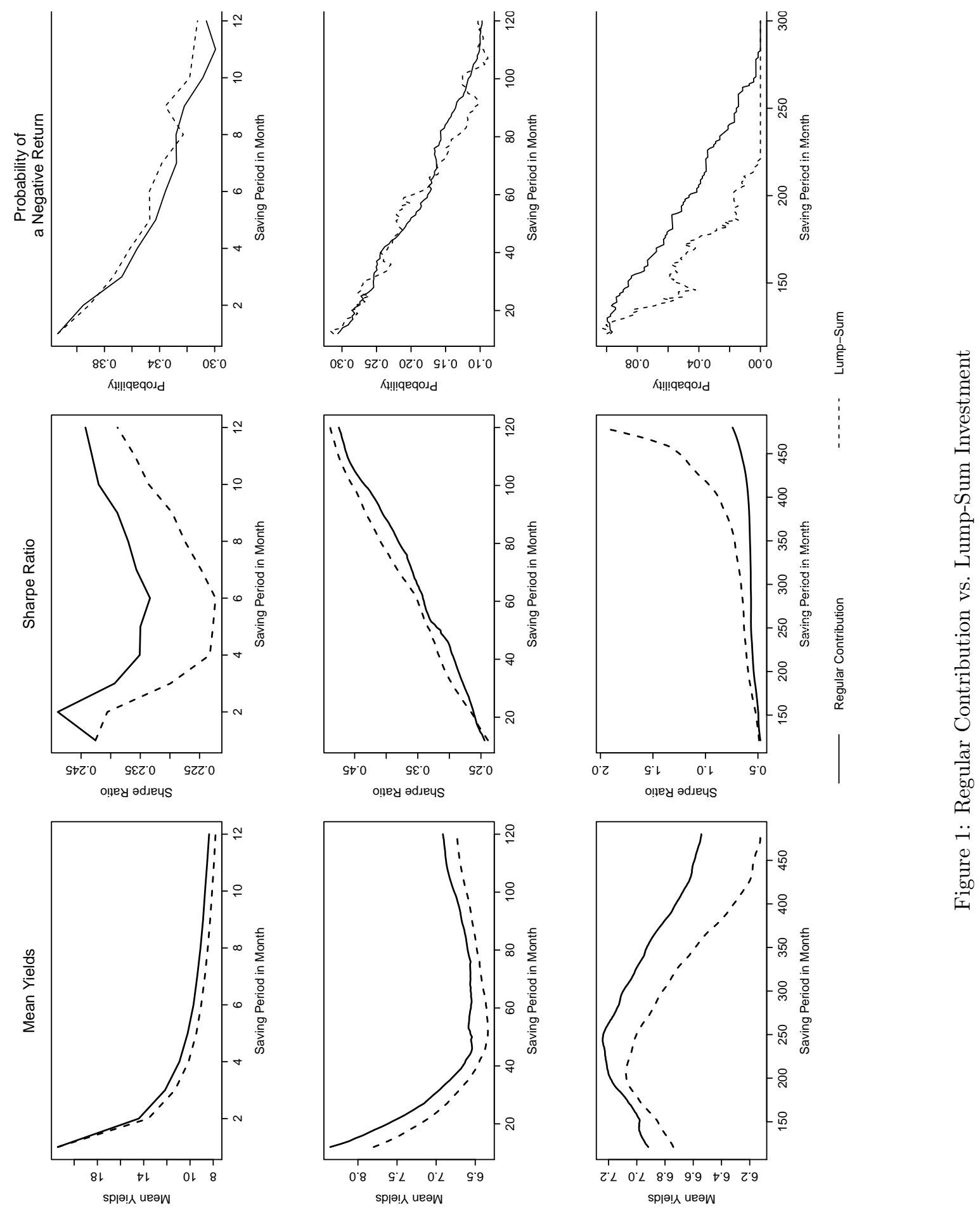

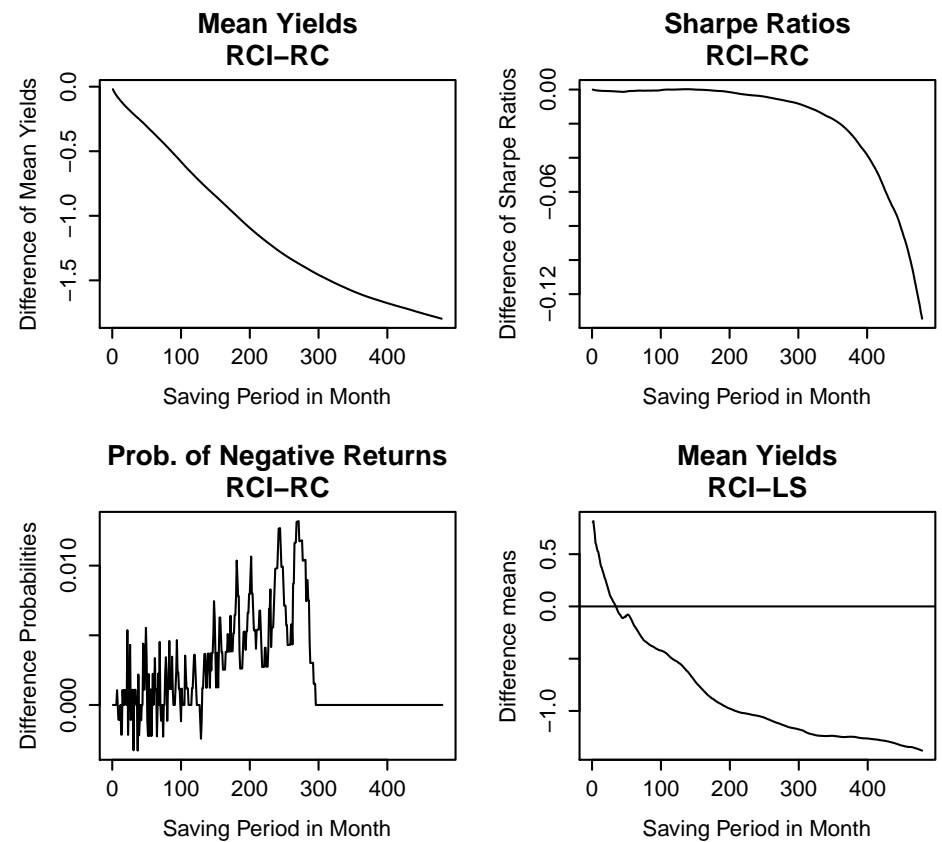

Figure 2: Regular Contribution with $\mathrm{g}=3.67$ and $\mathrm{g}=0$ compared

the Sharpe ratios, that is the differences as a ratio the Sharpe ratio of LS, are very small, never exceeding five percentage points. For longer horizons LS has a more favorable Sharpe ratio than RC. And, the difference in the Sharpe ratio is growing, from about 25 years even at an exponentially rising rate. For the longest investment horizon the Sharpe ratio of LS is 1.98 and for RC 0.74, that is the Sharpe ratio is about 160 percent higher for LS than for RC.

The probability of negative returns is about the same for horizons up to ten years, falling almost linearly from 41 percent for one month horizons to about ten percent for 10 year horizons. The probability of a loss is considerably lower for longer horizons. Both probabilities fall to zero, however, LS reaches this level after only 221 months, while it takes five more years for RC (284 months).

A more realistic scenario for $\mathrm{RC}$ involves monthly contributions that increase over time (RCI). This is mainly because investors try to compensate for inflation and/or as a consequence of income increases over the life cycle. To account for this, the monthly contributions are allowed to increase by the average month-onmonth inflation rate over the respective interval. The inflation is calculated as the geometric mean of monthly growth rates of the CPI, giving an annualized growth rate of 3.7 percent. As $(1+g)^{12}=3.7 \%, g=0.302 \%$. The first contribution is such that $1+g$, the second one $(1+g)^{2}$, and so forth. 
The plots in figure 2 compare RCI to the RC and to LS. The first plot in the first row shows the difference of the mean yields of RCI and RC, the second plot in the first row the difference in the Sharpe ratios of RCI and $\mathrm{RC}$, the first plot in the second line the difference in the probabilities of negative returns of $\mathrm{RCI}$ and RC, and the second plot in the second row the difference of RCI to LS. The relative difference of RCI to the results of an LS investment with respect to the risk-measures, the Sharpe Ratio and the probability of negative returns are negligable and not plotted here.

With an expanding investment horizon the difference of mean returns of $\mathrm{RCI}$ and RC almost constantly declines to -1.8 percentage points for 480 month horizons. The difference in the Sharpe ratios of RCI and RC are always negative, and falling exponentially with the length of the investment horizon with a difference of -0.13 percentage points for an horizon of 480 months. As the maximum of the Sharpe ratio for $\mathrm{RC}$ is 0.74 (480 month horizon), the difference is considerable. The difference in the probability of negative returns is growing with the horizon, as well. The maximum difference being 1.39 percentage points for 271 month horizons. As the probabilities are lower the longer the horizons, this implies a 4.5 times higher probability when compared to RC. For RCI, the probability of negative returns being zero starts with horizons greater than 296 months, whereas for $\mathrm{RC}$ this is already the case for horizons greater than 283 months.

Finally, for longer horizons, the average returns are lower, even when compared to LS. While the returns for shorter horizons up to 35 month horizon for RCI are still bigger than for LS, LS yields are higher for longer investment horizons and the difference is growing to 1.4 percentage points (480 month horizon). For a 40 years horizon, this implies a terminal value for RCI that is 30 percent lower than for LS.

\subsection{Before peaks and troughs}

As the focus of this paper is to analyze the differences in timing between $\mathrm{RC}$ and LS, the correct prediction of economic turning points is not addressed here. The author is well-aware that the dating is best done retrospectively when all data are available and most of the data revisions common to macroeconomic time series are over. Assuming the estimated peaks and troughs of the NBER are known to the investor the question the following lines try to answer is when an investor should leave or (re-)enter the market to maximize profits. Figure 3 gives the thirteen contractions of the US business cycle together with the logarithm of the DJIA from January 1934 to December 2012. The contractions, that is the time from peak to trough, range from six to eighteen months. Except for the interval between February 1945 and October 1945 all contractions are preceded by sharp drops of the DJIA. Prior to a trough, the DJIA is picking up again.

Table 1 displays the results of regular and lump-sum investments in the run-up to a peak. As it is unclear ex-ante how many months before a peak the switch should take place, the analysis compares the results for $d=1, \ldots, 24$ 


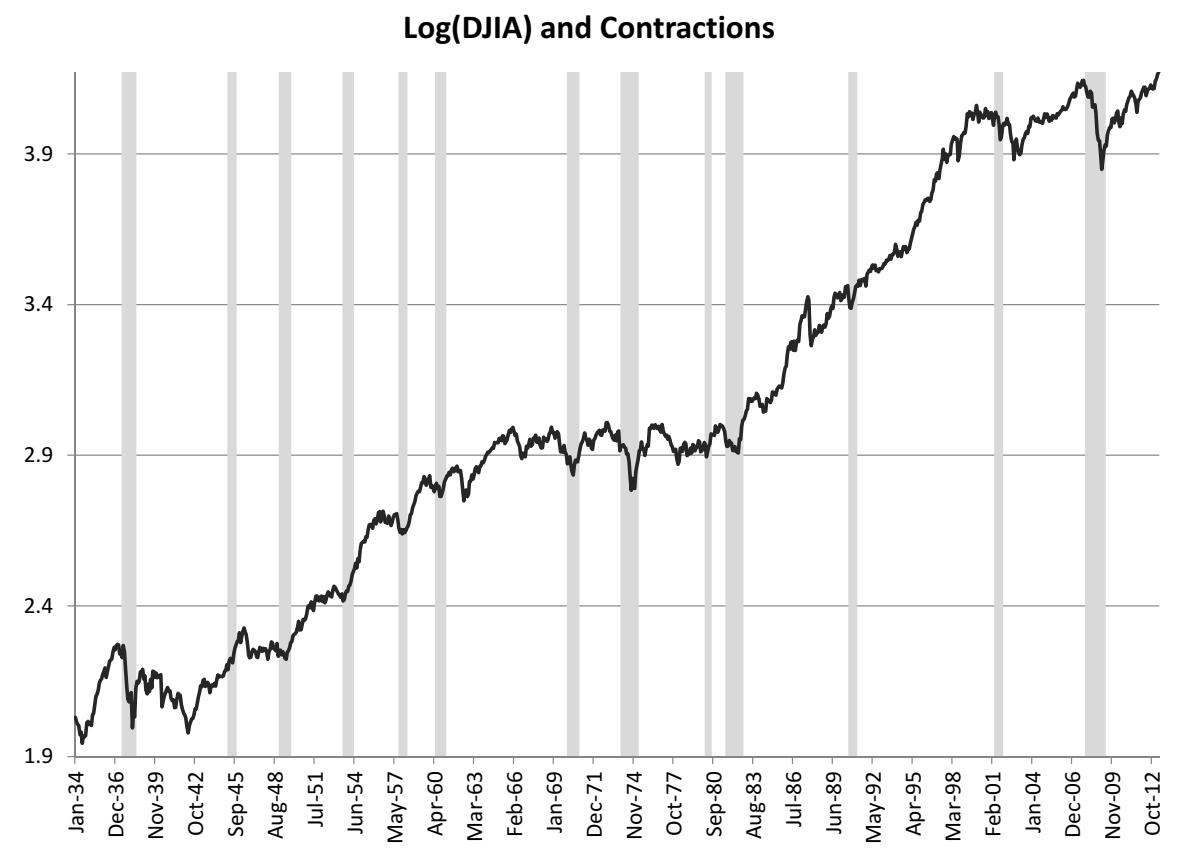

Figure 3: $\log$ (DJIA) and Contractions 
months before a peak. For $d=24$, for example, the results for an investment that starts 24 months before and ends at a peak are given. As DCA is an actual alternative to LS, and is based on regular purchases like RC, it is included in the analysis. The second to the fourth column give the mean excess returns (ER) of LS, RC, and DCA over the riskless rate. The fifth and sixth column give the mean differences of DCA and LS (DCALS), respectively RC and LS (RCLS). The $t$-values are given in parenthesis, where one, two, and three stars indicate significance at the ten, five, and one percent level of the one-sided t-tests.

LS investors have more time to leave the stock market without a loss than $\mathrm{RC}$ and DCA before a contraction. In line with the literature, the mean ER of LS, RC, and DCA decrease the smaller $d$ becomes. However, the first negative means appear for LS when $d=13$, whereas the first negative means appear already for $d=21$ for RC and DCA. Due to the volatility increase around the peak, the t-statistics are mostly insignificant, although the absolute values of the means are partially very high. The maximum absolute mean return of $-10.63 \%$ for $d=1$, for example, where LS, RC, and DCA are conceptionally identical, is not significantly negative. Furthermore, only the positive t-values of ER represent Sharpe ratios, whereas negative values do not have such an interpretation.

Here again, the returns of LS are little informative for regular investors. The differences of RC and LS are negative for almost all $d$ being significant for $13 \leq d \leq 24$, mostly at the five percent level. This implies that returns are higher for LS. DCA is inferior to LS, DCALS being negative for $12 \leq d \leq 24$. For $18 \leq d \leq 24$ the differences are mostly significant at the five percent level. Still, they are mostly positive although not significant for the remaining $d$ for $1 \leq d \leq 11$.

Table 2 shows the results before a trough. RC and DCA investors can return to the stock market earlier than LS investors. Being in a contraction, LS-ER for $6 \leq d \leq 24$ are negative, turn positive and increase the smaller the interval to the trough, to a maximum of about 56 percent for $d=1$. They are significantly positive for $d \leq 4$ at the five percent level. RC-ER and DCA-ER follow a similar pattern. For both, however, the mean excess returns turn positive already five months before those of LS, that is for $d \leq 11$. They are significantly positive three months earlier, for $d \leq 7$, as well.

RCLS is positive except for $d=2$, and it is significant at least at the five percent level for $4 \leq d \leq 18$ reaching a maximum of 14.5 percentage points for $d=7$. As the invested money is assumed to be available at the same time for DCA and LS, they are directly comparable. DCALS is positive and significant at the five percent level for nearly all $d$ except for $2 \leq d \leq 4$ reaching a maximum of 10.5 percentage points for $d=9$. DCA is significantly superior to LS and to the risk-free rate at the same time for intervals starting six and seven months before a trough. Thus, for these months DCA is a relevant alternative to LS. Still, for $d=2,3$ DCALS are negative and significant. For these two months, as both, DCA and LS are significantly positive, DCA is no alternative to LS. 


\begin{tabular}{|c|c|c|c|c|c|c|c|c|c|c|}
\hline d & \multicolumn{2}{|c|}{ LS-ER } & \multicolumn{2}{|c|}{ RC-ER } & \multicolumn{2}{|c|}{ DCA-ER } & \multicolumn{2}{|c|}{ RCLS } & \multicolumn{2}{|c|}{ DCALS } \\
\hline 24 & 4.31 & $(1.64)^{*}$ & 0.86 & $(0.36)$ & 0.36 & $(0.29)$ & -3.14 & $(-2.64)^{* * *}$ & -3.96 & $(-2.43)^{* *}$ \\
\hline 23 & 4.14 & $(1.56)^{*}$ & 0.54 & $(0.23)$ & 0.19 & $(0.15)$ & -3.31 & $(-2.82)^{* *}$ & -3.95 & $(-2.40)^{* *}$ \\
\hline 22 & 3.14 & $(1.20)$ & 0.19 & $(0.08)$ & 0.00 & $(0.00)$ & -2.67 & $(-2.03) * *$ & -3.13 & $(-1.87)^{* *}$ \\
\hline 21 & 2.82 & $(1.20)$ & -0.11 & $(-0.05)$ & -0.16 & $(-0.12)$ & -2.67 & $(-2.13)^{* *}$ & -2.97 & $(-2.06)^{* *}$ \\
\hline 20 & 1.94 & $(0.81)$ & -0.42 & $(-0.17)$ & -0.32 & $(-0.25)$ & -2.11 & $(-1.62)^{*}$ & -2.25 & $(-1.53)^{*}$ \\
\hline 19 & 1.60 & $(0.63)$ & -0.68 & $(-0.28)$ & -0.45 & $(-0.35)$ & -2.04 & $(-1.57)^{*}$ & -2.05 & $(-1.32)$ \\
\hline 18 & 1.75 & $(0.72)$ & -0.94 & $(-0.38)$ & -0.59 & $(-0.44)$ & -2.46 & $(-2.57)^{* * *}$ & -2.34 & $(-1.80)^{* *}$ \\
\hline 17 & 0.92 & $(0.38)$ & -1.26 & $(-0.51)$ & -0.76 & $(-0.57)$ & -1.96 & $(-1.74)^{* *}$ & -1.68 & $(-1.26)$ \\
\hline 16 & 0.77 & $(0.31)$ & -1.54 & $(-0.61)$ & -0.91 & $(-0.67)$ & -2.09 & $(-1.48)^{*}$ & -1.68 & $(-1.12)$ \\
\hline 15 & 0.57 & $(0.23)$ & -1.85 & $(-0.71)$ & -1.07 & $(-0.76)$ & -2.19 & $(-1.44)^{*}$ & -1.64 & $(-1.05)$ \\
\hline 14 & 0.97 & $(0.36)$ & -2.20 & $(-0.82)$ & -1.28 & $(-0.87)$ & -2.93 & $(-2.36)^{* *}$ & -2.24 & $(-1.47)^{*}$ \\
\hline 13 & -0.20 & $(-0.08)$ & -2.69 & $(-0.98)$ & -1.58 & $(-1.05)$ & -2.27 & $(-1.97)^{* *}$ & -1.37 & $(-1.11)$ \\
\hline 12 & -0.02 & $(-0.01)$ & -3.10 & $(-1.09)$ & -1.83 & $(-1.16)$ & -2.89 & $(-1.59)^{*}$ & -1.81 & $(-0.94)$ \\
\hline 11 & -2.95 & $(-1.01)$ & -3.66 & $(-1.24)$ & -2.15 & $(-1.31)$ & -0.54 & $(-0.31)$ & 0.8 & $(0.44)$ \\
\hline 10 & -2.92 & $(-1.02)$ & -3.78 & $(-1.23)$ & -2.25 & $(-1.30)$ & -0.72 & $(-0.38)$ & 0.68 & $(0.38)$ \\
\hline 9 & -1.92 & $(-0.63)$ & -3.94 & $(-1.20)$ & -2.37 & $(-1.28)$ & -1.92 & $(-0.99)$ & -0.45 & $(-0.25)$ \\
\hline 8 & -1.24 & $(-0.35)$ & -4.39 & $(-1.26)$ & -2.69 & $(-1.34)^{*}$ & -3.09 & $(-1.54)^{*}$ & -1.45 & $(-0.69)$ \\
\hline 7 & -5.30 & $(-1.67)^{*}$ & -5.24 & $(-1.42)^{*}$ & -3.21 & $(-1.50)^{*}$ & 0.11 & $(0.05)$ & 2.09 & $(1.04)$ \\
\hline 6 & -6.26 & $(-1.83)^{* *}$ & -5.10 & $(-1.23)$ & -3.24 & $(-1.32)$ & 1.20 & $(0.57)$ & 3.03 & $(1.68)^{*}$ \\
\hline 5 & -3.49 & $(-0.87)$ & -4.50 & $(-0.95)$ & -3.04 & $(-1.07)$ & -0.99 & $(-0.52)$ & 0.45 & $(0.25)$ \\
\hline 4 & -3.51 & $(-0.74)$ & -4.85 & $(-0.92)$ & -3.43 & $(-1.03)$ & -1.34 & $(-0.53)$ & 0.08 & $(0.03)$ \\
\hline 3 & -6.38 & $(-1.17)$ & -5.36 & $(-0.86)$ & -4.12 & $(-0.98)$ & 0.99 & $(0.34)$ & 2.25 & $(0.87)$ \\
\hline 2 & 1.82 & $(0.23)$ & -3.36 & $(-0.42)$ & -3.25 & $(-0.53)$ & -5.22 & $(-1.73)^{* *}$ & -5.07 & $(-1.55)^{*}$ \\
\hline 1 & -10.63 & $(-0.95)$ & -10.63 & $(-0.95)$ & -10.63 & $(-0.95)$ & 0.00 & NA & 0.00 & $\mathrm{NA}$ \\
\hline
\end{tabular}

ER is the mean difference of LS, DCA, and RC, and the risk-free rate. $\mathrm{d}$ is the \# of mths. before a peak and the length of the intervals for which the results are calculated. DCALS and RCLS is the mean difference of the returns of DCA and LS, and RC and LS, respectively; t-val. are given in (). *,**, ${ }^{* *}$ ind. significance at the $10 \%, 5 \%$, and $1 \%$ level.

Table 1: Before a peak 


\begin{tabular}{|c|c|c|c|c|c|c|c|c|c|c|}
\hline $\mathrm{d}$ & \multicolumn{2}{|c|}{ LS-ER } & \multicolumn{2}{|c|}{ RC-ER } & \multicolumn{2}{|c|}{ DCA-ER } & \multicolumn{2}{|c|}{ RCLS } & \multicolumn{2}{|c|}{ DCALS } \\
\hline 24 & -6.49 & $(-2.02)^{* *}$ & -6.31 & $(-1.59)^{*}$ & -3.34 & $(-1.60)^{*}$ & 0.03 & $(-0.02)$ & 3.15 & $(2.07)^{*}$ \\
\hline 23 & -7.56 & $(-2.24)^{* *}$ & -6.27 & $(-1.55)^{*}$ & -3.33 & $(-1.56)^{*}$ & 1.11 & $(-0.68)$ & 4.23 & $(2.51)^{* * *}$ \\
\hline 22 & -7.38 & $(-2.08)^{* *}$ & -6.14 & $(-1.49)^{*}$ & -3.26 & $(-1.49)^{*}$ & 1.06 & $(0.74)$ & 4.12 & $(2.41)^{* *}$ \\
\hline 21 & -7.93 & $(-2.33)^{* *}$ & -6.00 & $(-1.43)^{*}$ & -3.21 & $(-1.43)^{*}$ & 1.73 & $(1.18)$ & 4.72 & $(3.11)^{* * *}$ \\
\hline 20 & -7.47 & $(-2.10)^{* *}$ & -5.78 & $(-1.35)^{*}$ & -3.11 & $(-1.36)^{*}$ & 1.48 & $(0.89)$ & 4.36 & $(2.50)^{* * *}$ \\
\hline 19 & -8.55 & $(-2.16)^{* *}$ & -5.58 & $(-1.27)$ & -3.02 & $(-1.28)$ & 2.75 & $(1.66)^{*}$ & 5.53 & $(2.70) * * *$ \\
\hline 18 & -8.99 & $(-2.29)^{* *}$ & -5.23 & $(-1.17)$ & -2.86 & $(-1.18)$ & 3.52 & $(2.02)^{* *}$ & 6.13 & $(3.07)^{* * *}$ \\
\hline 17 & -9.56 & $(-2.35)^{* *}$ & -4.77 & $(-1.04)$ & -2.62 & $(-1.05)$ & 4.56 & $(2.30)^{* *}$ & 6.94 & $(3.17)^{* * *}$ \\
\hline 16 & -9.35 & $(-2.34)^{* *}$ & -4.15 & $(-0.88)$ & -2.32 & $(-0.90)$ & 4.96 & $(2.30)^{* *}$ & 7.03 & $(3.31)^{* * *}$ \\
\hline 15 & -9.38 & $(-2.51) * * *$ & -3.42 & $(-0.7)$ & -1.96 & $(-0.73)$ & 5.71 & $(3.00)^{* * *}$ & 7.42 & $(4.69)^{* * *}$ \\
\hline 14 & -9.15 & $(-2.15)^{* *}$ & -2.53 & $(-0.49)$ & -1.51 & $(-0.54)$ & 6.38 & $(3.98)^{* * *}$ & 7.64 & $(4.24)^{* * *}$ \\
\hline 13 & -7.71 & $(-1.70)^{*}$ & -1.47 & $(-0.28)$ & -0.96 & $(-0.33)$ & 6.00 & $(2.90)^{* * *}$ & 6.75 & $(3.06)^{* * *}$ \\
\hline 12 & -7.83 & $(-1.54)^{*}$ & -0.37 & $(-0.07)$ & -0.41 & $(-0.13)$ & 7.21 & $(3.55)^{* * *}$ & 7.43 & $(2.90) * * *$ \\
\hline 11 & -7.78 & $(-1.59)^{*}$ & 1.04 & $(-0.18)$ & 0.33 & $(-0.11)$ & 8.56 & $(3.62)^{* * *}$ & 8.11 & $(3.27)^{* * *}$ \\
\hline 10 & -7.45 & $(-1.26)$ & 2.90 & $(-0.49)$ & 1.32 & $(-0.40)$ & 10.09 & $(4.07)^{* * *}$ & 8.78 & $(2.71)^{* * *}$ \\
\hline 9 & -7.84 & $(-1.33)^{*}$ & 5.33 & $(-0.87)$ & 2.67 & $(-0.78)$ & 12.90 & $(4.40)^{* * *}$ & 10.51 & $(3.15)^{* * *}$ \\
\hline 8 & -5.09 & $(-0.80)$ & 8.87 & $(1.37)^{*}$ & 4.63 & $(-1.27)$ & 13.71 & $(3.87)^{* * *}$ & 9.73 & $(2.53)^{* * *}$ \\
\hline 7 & -1.54 & $(-0.27)$ & 13.27 & $(1.91)^{* *}$ & 7.06 & $(1.79)^{* *}$ & 14.55 & $(3.41)^{* * *}$ & 8.61 & $(2.39)^{* *}$ \\
\hline 6 & 4.78 & $(-0.84)$ & 18.94 & $(2.37)^{* *}$ & 10.23 & $(2.23) * *$ & 13.9 & $(3.58)^{* * *}$ & 5.46 & $(2.05)^{* *}$ \\
\hline 5 & 11.47 & $(1.46)^{*}$ & 25.50 & $(2.70)^{* * *}$ & 14.02 & $(2.56)^{* * *}$ & 13.76 & $(3.72)^{* * *}$ & 2.55 & $(0.73)$ \\
\hline 4 & 20.17 & $(2.21)^{* *}$ & 33.69 & $(3.08)^{* * *}$ & 19.2 & $(2.96)^{* * *}$ & 13.28 & $(2.64)^{* * *}$ & -0.97 & $(-0.22)$ \\
\hline 3 & 39.57 & $(2.72)^{* * *}$ & 44.85 & $(3.27)^{* * *}$ & 27.06 & $(3.22)^{* * *}$ & 5.12 & $(1.34)^{*}$ & -12.51 & $(-1.86)^{* *}$ \\
\hline 2 & 53.76 & $(3.29)^{* * *}$ & 52.08 & $(3.74)^{* * *}$ & 36.16 & $(3.79)^{* * *}$ & -1.74 & $(-0.28)$ & -17.61 & $(-2.11)^{* *}$ \\
\hline 1 & 56.16 & $(3.17)^{* * *}$ & 56.16 & $(3.17)^{* * *}$ & 56.16 & $(3.17)^{* * *}$ & 0.00 & NA & 0.00 & NA \\
\hline
\end{tabular}

$\mathrm{ER}$ is the mean difference of LS, DCA, and RC, and the risk-free rate. $\mathrm{d}$ is the \# of mths. before a peak and the length of the intervals for which the results are calculated. DCALS and RCLS is the mean difference of the returns of $\mathrm{DCA}$ and $\mathrm{LS}$, and $\mathrm{RC}$ and $\mathrm{LS}$, respectively; $\mathrm{t}-\mathrm{val}$. are given in ().*,**,*** ind. significance at the $10 \%, 5 \%$, and $1 \%$ level.

Table 2: Before a trough 


\section{Conclusion}

Using lump-sum investment returns to address regular contributor's investment issues is prone to lead to wrong decisions. While the return of a lump-sum investment only depends on the buying and selling price of an asset over the investment horizon, investments based on regular contributions crucially depend on the prices in between, as well. Furthermore, each contribution has its own investment horizon. Many private investors are regular contributors laying back part of their monthly income, e.g. as an old-age provision. Most of the information on returns of investment alternatives publicly available is for lump-sum investors and thus only of relevance, when it comes to taking decisions on wealth already accumulated. However, if regular investment decisions are concerned, the same information can be misleading. This paper contrasts the mean returns of lump-sum and a regular investments into the Dow Jones Industrial Average for investment horizons ranging from one month to 40 years for all possible intervals from 1934 to 2012. The difference in means, the risk-return-ratio, and the probability of negative returns of the alternatives increase with the length of the investment horizon. For horizons of 40 years the expected returns are thirty percent lower for regular investors than the commonly used yields would imply. Most notably the Sharpe ratio of lump-sum investments is more than double the one of regular investments for very long investment horizons. For regular investors, the risk of negative returns ceases only for horizons that are five years longer. Furthermore, when the timing of a market entrance or exit around business cycle turning points is concerned, the different return concepts lead to different results. While a regular investor has more time to leave in the run-up to a peak, a lump-sum investor may re-enter the market earlier before a trough. Risk and return as well as timing in the run-up of business cycle turning points are considerably different for lump-sum and regular investments. Thus, the commonly used lump-sum returns are misleading when applied to regular contributor's investment decisions. 


\section{References}

Ronald J Balvers and Douglas W Mitchell. Autocorrelated returns and optimal intertemporal portfolio choice. Management Science, 43(11):1537-1551, 1997.

M.J. Brennan, F. Li, and W.N. Torous. Dollar cost averaging. Review of Finance, 9(4):509-535, 2005.

G.M. Constantinides. A note on the suboptimality of dollar-cost averaging as an investment policy. Journal of Financial and Quantitative Analysis, 14(2): 443-450, 1979.

Michael DeStefano. Stock returns and the business cycle. Financial Review, 39 (4):527-547, 2004.

Ilia D Dichev. What are stock investors' actual historical returns? evidence from dollar-weighted returns. The American Economic Review, pages 386401, 2007.

Eugene F Fama and Kenneth R French. Business conditions and expected returns on stocks and bonds. Journal of financial economics, 25(1):23-49, 1989.

K.B. Leggio and D. Lien. An empirical examination of the effectiveness of dollar-cost averaging using downside risk performance measures. Journal of Economics and Finance, 27(2):211-223, 2003.

Burton G Malkiel. A random walk down Wall Street: the time-tested strategy for successful investing. WW Norton \& Company, 2003.

AG Malliaris and Mary E Malliaris. Investment principles for individual retirement accounts. Journal of Banking \& Finance, 32(3):393-404, 2008.

M. Rozeff. Lump-sum investing versus dollar-averaging. Journal of Portfolio management, pages 45-50, 1994.

Jeremy J Siegel. Does it pay stock investors to forecast the business cycle? The Journal of Portfolio Management, 18(1):27-34, 1991.

WJ Trainor. Within-horizon exposure to loss for dollar cost averaging and lump sum investing. Financial Services Review, 14(4):319, 2005.

Steven Vanduffel, Ales Ahcan, Luc Henrard, and Mateusz Maj. An explicit option-based strategy that outperforms dollar cost averaging. International Journal of Theoretical and Applied Finance, 15(02), 2012. 